\title{
Constraints on priming in spatial memory: Naturally learned versus experimentally learned environments
}

\author{
TIMOTHY P. MCNAMARA, JEANETTE ALTARRIBA, MICHAEL BENDELE, \\ SUSAN C. JOHNSON, and KEITH N. CLAYTON \\ Vanderbilt University, Nashville, Tennessee
}

\begin{abstract}
In four experiments, we explored constraints on priming in spatial memory. In Experiments 1 and 2, subjects who were familiar with the locations of buildings on the Vanderbilt campus participated in a recognition test. The subjects' task was to decide whether or not named buildings were on the campus. Foils in this recognition test were realistic but fictional names of buildings. In principle, the subjects could have performed this task without using spatial knowledge; in fact, they must not have used spatial knowledge, because there was no evidence of priming in recognition as a function of the spatial relations between buildings on the campus. This result differs from those obtained in earlier experiments that have examined memory of spatial layouts learned in laboratory settings. In Experiment 3, the fictional foils were replaced by names of buildings in an area of the campus separated geographically from the main campus. Evidently, this change induced subjects to retrieve spatial knowledge, because the spatial priming effect materialized. A fourth experiment replicated the above findings in a single experiment and demonstrated that spatial priming could be obtained when the configuration of buildings was learned experimentally. These results are explained by appealing to the "decontextualization" that takes place in memory over time.
\end{abstract}

In several studies, we have used priming in item recognition to investigate the structure and the content of spatial memory (McNamara, 1986; McNamara, Hardy, \& Hirtle, 1989; McNamara \& LeSueur, in press; McNamara, Ratcliff, \& McKoon, 1984). In a typical experiment, subjects learn the locations of objects in a spatial layout, and then participate in a recognition test. Object names are displayed one at a time on a computer screen; the subjects' task is to decide whether or not the named object was in the layout. The variable of interest is priming between sequential items in the recognition test as a function of the spatial relations between corresponding objects in the layout. In one study, for example, it has been shown that locations in the same region of a spatial layout prime each other more than do locations in different regions, even when Euclidean distance is held constant (McNamara, 1986). These and other findings (e.g., Hirtle \& Jonides, 1985; McNamara et al., 1989; Stevens \& Coupe, 1978) suggest that spatial memory is organized hierarchically.

Recognition priming is particularly useful for investigating spatial memory because it is not influenced by retrieval

This research was supported in part by National Science Foundation Grant BNS-8417741 and National Institute of Mental Health Grant 5 T32-MH15792-08. This article has benefited greatly from the comments provided by Alice F. Healy and three anonymous reviewers. Susan C. Johnson is now at the Massachusetts Institute of Technology. Requests for reprints should be sent to Timothy P. McNamara, Department of Psychology, Vanderbilt University, Nashville, TN 37240. strategies. Ratcliff and McKoon (1981) have shown that priming in memory for text has a very fast onset and is insensitive to the probability of related items. McNamara et al. (1989) have demonstrated that inhibition does not occur in spatial priming at brief $(150$-msec $)$ stimulus onset asynchronies (SOA). These qualities indicate that priming is an automatic process (as defined by Posner \& Snyder, 1975a, 1975b). Consequently, priming in recognition should be informative about the structure and the content of memory, but not about strategies and inferences employed at the time of the test.

Although spatial priming has been an effective tool for examining memory for experimentally learned environments, there is evidence that spatial priming does not occur in memory for naturally learned environments. Merrill and Baird (1987) used a priming task to investigate memory of a university campus. In two experiments (Experiments 2 and 4), their subjects were shown pairs of place names separated in time by a $350-\mathrm{msec}$ SOA. The subjects' task was to decide whether or not both names were names of locations in Hanover, New Hampshire. On half of the trials, one name in a pair was a noncampus name. In Experiment 2, there seemed to be evidence of spatial priming, in that pairs of names that were related spatially and functionally were classified faster than pairs that were related only functionally. Responses to the latter pairs were faster than responses to unrelated pairs (by $63 \mathrm{msec}$ ), but the difference was not statistically reliable. However, in Experiment 4, there seemed to be very little evidence of spatial priming, in that pairs of 
names related spatially (but not functionally) were classified faster than were unrelated pairs (by $27 \mathrm{msec}$ ), but this difference did not approach significance. Overall, the evidence for purely spatial priming was weak.

There are several features of Merrill and Baird's (1987) experiments that might have contributed to their failure to find clear evidence of spatial priming. First, these experiments did not test subjects' knowledge of the locations of buildings on campus: If the subjects did not have accurate knowledge about the locations of buildings, then spatial priming should not have occurred. ${ }^{1}$ Second, the power of these experiments was only moderate: The numbers of subjects were fairly small and the standard errors of response times were quite large. Finally, Experiments 2 and 4 used different procedures (sorting vs. free association) to classify pairs as related and unrelated, so results from these experiments may not be comparable.

Because Merrill and Baird's (1987) results pointed to important differences between experimental and natural spatial memories but seemed inconclusive, we decided to pursue the problem further. There are three significant methodological differences between the experiments reported here and those conducted by Merrill and Baird. First, we used a recognition test rather than Merrill and Baird's classification task. Priming in recognition had always appeared in our studies of experimental spatial memories, so it seemed wise to use the same task in these investigations of natural spatial memories. Second, we tested individual subjects on their knowledge of the campus in all of the present experiments. Third, we restricted our investigation to purely spatial relations so as not to complicate the design unnecessarily (but see McNamara \& LeSueur, in press).

\section{EXPERIMENT 1}

The first experiment was modeled after our earlier studies of spatial memory, but instead of having subjects learn a novel spatial layout, we recruited subjects (juniors and seniors at Vanderbilt) who were likely to be familiar with the locations of buildings on campus. The subjects were given a recognition test in which their task was to decide whether or not a named building was on the campus. The foils in this experiment were analogous to the foils used in previous research: realistic but fictional names of campus buildings. In principle, the subjects could perform this task without consulting spatial memory. The same observation holds for all of our earlier work, however, and yet we have never failed to find spatial priming in recognition.

\section{Method}

Subjects. The subjects were 18 juniors and seniors at Vanderbilt University. Advanced students were selected in an attempt to increase the likelihood that the subjects' knowledge of the campus would be well developed and reasonably accurate. The subjects were compensated for their participation in the experiment with course credit.
Materials. Thirty-eight locations on the Vanderbilt University campus were selected to be used as stimuli: 12 served as "targets," 18 served as "primes," and 8 served as "fillers" in the recognition test. Primes preceded targets in the recognition test (see procedures below). Fillers were not used in the experimental conditions. In addition, 16 names of fictional places were generated and used as foils in the recognition test. A map of the relative locations of campus buildings (including buildings used in Experiments 3 and 4) can be found in Figure 1.

Each target could be paired with two primes, one of which was a building close to the target and the other of which was a building far from the target. For example, the target Neely had as its close prime Alumni Hall and as its far prime Wesley. The average distance between targets and their close primes was $339 \pm 47 \mathrm{ft}$ and the average distance between targets and their far primes was $1,518 \pm 72 \mathrm{ft}$ (distances were measured between the centers of buildings). Each of the 12 target buildings had a unique close prime, but each target shared its far prime with one other target building. That is, there were six far primes, one for each of two target buildings. Far primes were shared in this manner to reduce the number of buildings required for the design. The targets Neely and Rand, for example, shared the far prime Wesley. A list of targets, primes, fillers, and foils can be found in Appendix A.

Primes were selected so that they shared a minimum of functional and semantic properties with targets. For example, administration buildings did not prime administration buildings, office buildings did not prime office buildings, dormitories did not prime dormitories, and libraries did not prime libraries. For the most part, buildings used for classes did not prime other buildings used for classes. In the five cases in which this rule was violated (out of a total of 24 prime-target pairs), the prime and the target buildings did not contain classes from the same department. Moreover, in two of these cases (Law School and Divinity School), the buildings contained graduate but not undergraduate courses (only undergraduates were used as subjects). Overall, functional and semantic relations between primes and targets were very weak, if they existed at all.

Two recognition-test lists were constructed. On one list, a target (e.g., Neely) was preceded by its close prime (Alumni Hall) and on the other list, the target was preceded by its far prime (Wesley). Hence, these test lists contained exactly the same target buildings and half of the same primes: Close primes on one list did not appear on the other list, but far primes appeared on both lists, although paired with different targets. Foils and fillers were identical on the two lists. The lists were constructed so that (1) names appeared only once on a list, (2) no target appeared earlier than the fourth test position, and (3) targets in the same condition were separated by at least three trials. Each list contained six targets preceded by close primes and six targets preceded by far primes. In addition, there were 16 foils and 8 fillers, producing 48 recognition trials in all. The two lists were assigned to subjects in a fixed rotation determined by the order in which the subjects participated in the experiment. Each list was seen by 9 subjects.

Procedure. The experimenter pretested each subject on his or her knowledge of the locations of buildings on the Vanderbilt campus. The experimenter pointed to unlabeled locations on a map of the campus; the subject's task was to provide the name of the building at that location. In order to participate in the experiment, a subject had to name 27 out of 30 locations correctly. These 30 locations were the locations of primes and targets used in the recognition test. All 18 subjects passed the knowledge test.

In a separate session and on a different day from the pretest, the subjects were given a recognition test for campus locations. Names of locations were presented one at at time on a computer screen; the subjects' task was to decide whether or not the named location was on the campus. The subjects pressed the " $\mathrm{m}$ " key to respond "yes" and the "z" key to respond "no." Both speed and accuracy 


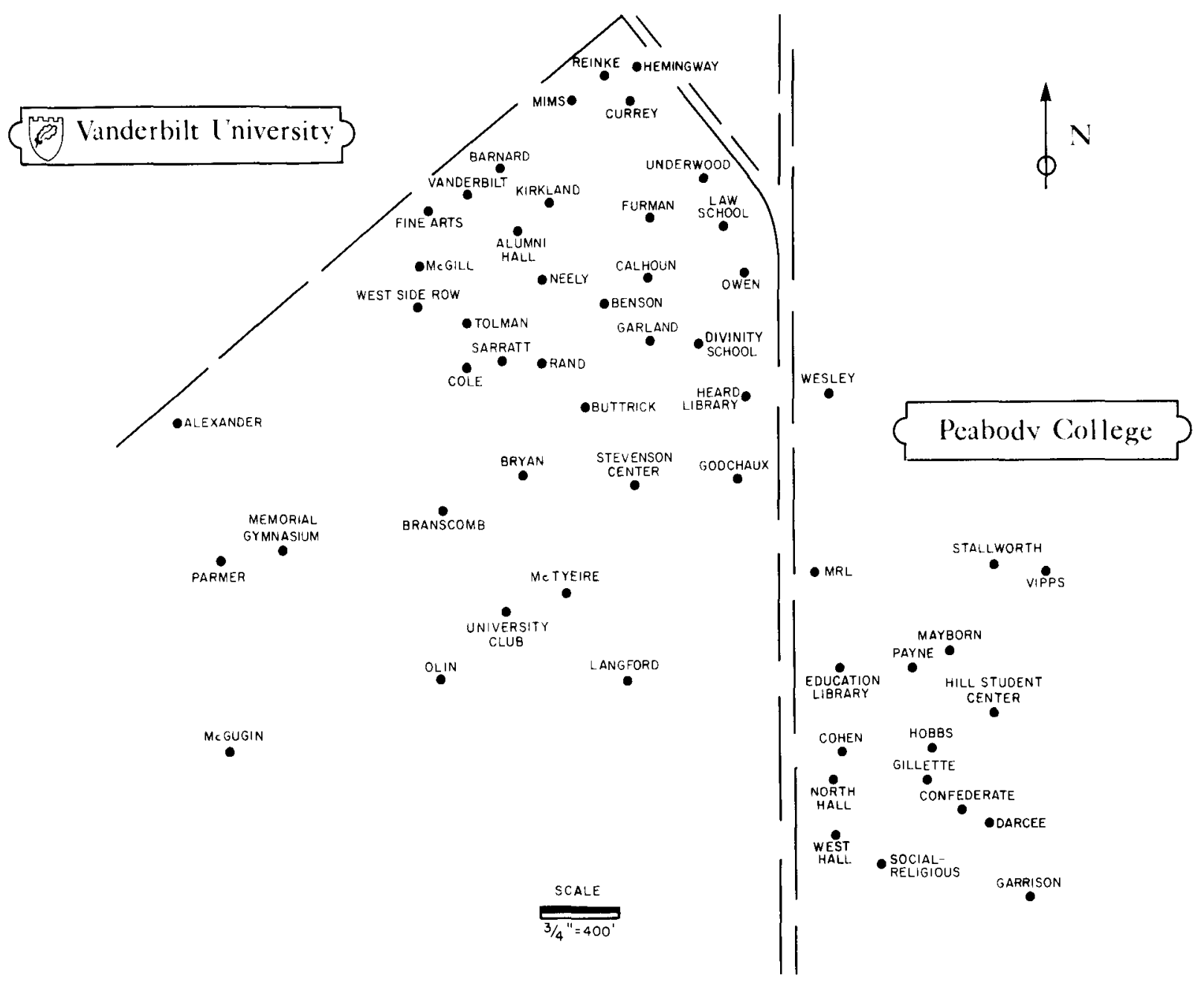

Figure 1. A map of the relative locations of buildings on the Vanderbilt University campus. This map includes only the locations used in our experimental materials.

were emphasized. There was a response-stimulus interval of $150 \mathrm{msec}$. The recognition test was preceded by a practice test, in which the subjects distinguished names of U.S. states from names of foreign countries. The procedures in the practice test were the same as those in the experimental recognition test. An experimental session (excluding the pretest) required about $15 \mathrm{~min}$.

\section{Results}

Mean correct response latencies and mean error rates for the targets in each of the two conditions were analyzed. Only correct responses preceded by correct responses were included in analyses of latencies. In addition, latencies exceeding $2.0 \mathrm{sec}$ were excluded from analyses of response latencies. Out of 213 responses that met the first condition (correct responses preceded by correct responses), 3 were classified as outliers.

The mean latency for targets primed by a close building was $777 \mathrm{msec}$, and the mean latency for targets primed by a far building was $781 \mathrm{msec}[t(17)=0.21, S E D=$ $19.2 \mathrm{msec}]{ }^{2}$ There was only one error across subjects and items, and it occurred on a target primed by a neighboring building. In short, there was no evidence of prim- ing in the recognition test as a function of the physical distance between buildings on campus.

Mean correct response latencies and mean error rates were $870 \pm 23 \mathrm{msec}$ and $0.9 \pm 0.7 \%$ for primes, $972 \pm$ $28 \mathrm{msec}$ and $2.8 \pm 1.0 \%$ for foils, and $1,029 \pm 50 \mathrm{msec}$ and $25.7 \pm 3.7 \%$ for fillers. The mean latency for errors was $1,155 \pm 112 \mathrm{msec}$ (excluding a single latency of $11 \mathrm{sec})$.

\section{Discussion}

The results of Experiment 1 replicated Merrill and Baird's (1987) findings, but they differed from the results obtained in our previous investigations of experimental spatial memories (McNamara, 1986; McNamara et al., 1989; McNamara \& LeSueur, in press; McNamara et al., 1984). Before exploring the causes of these contradictory results, we thought it best to attempt to replicate the results of Experiment 1 with slightly modified procedures. Several subjects in Experiment 1 reported that they began the recognition test expecting to see names of buildings on which they were tested in the pretest. It is possible that 
at least some subjects were using their memories of the pretest to aid their recognition decisions. If the subjects were not using spatial memory in the recognition test, then spatial priming effects should not have appeared.

\section{EXPERIMENT 2}

The purpose of Experiment 2 was to replicate Experiment 1 using the same materials. The only difference between these experiments was that in Experiment 1, the building-location test was given before the experimental recognition test, whereas in Experiment 2, the buildinglocation test was given after the experimental recognition test (and in a more systematic manner).

\section{Method \\ Subjects. The subjects were 30 juniors and seniors at Vander- bilt University. The subjects were compensated for their participa- tion in the experiment with course credit. \\ Materials. The materials were the same as those used in Ex- periment 1. \\ Procedure. The subjects first participated in a practice test, in which they distinguished names of U.S. states from names of for- eign countries. The subjects then participated in the experimental recognition test. The procedures were identical to those of Experi- ment 1 . Following this recognition test, the subjects were tested on their knowledge of the locations of buildings on the Vanderbilt campus. The subjects received a map of the campus that contained 30 buildings circled. The names of these buildings were not present on the map. The subjects' task was to number each circled build- ing and then to write the number and the name of each building on a separate sheet of paper. An experimental session lasted about $30 \mathrm{~min}$.}

\section{Results}

Mean correct response latencies and mean error rates for the targets in each of the two conditions were analyzed. Only correct responses preceded by correct responses were included in these means. Latencies exceeding $2.0 \mathrm{sec}$ were excluded from the means. Out of 327 responses that met the first condition, 2 were classified as outliers.

The mean latency for targets primed by a close building was $765 \mathrm{msec}$, and the mean latency for targets primed by a far building was $757 \mathrm{msec}(S E D=19.9 \mathrm{msec})$. Error rates were $3.3 \%$ and $3.9 \%$, respectively $[t(29)=0.29$, $S E D=2.0 \%]$. As in Experiment 1, there was no evidence of spatial priming either in latencies or in error rates (indeed, the effect on latencies was in the wrong direction).

On the average, the subjects knew the correct locations and names of $82.9 \pm 3.4 \%$ of the 30 buildings on which they were tesed in the posttest. We tried conditionalizing latencies on the knowledge-test results (by excluding subjects whose knowledge of the campus was poor or by excluding target buildings on which subjects made errors in the knowledge test), but the results were the same. In other words, the absence of a spatial priming effect was not caused by incomplete knowledge of the campus.
An examination of the distance effect on the two recognition lists (employed for counterbalancing) revealed an interaction between distance and list. Mean latencies for the close and the far conditions were 763 and $811 \mathrm{msec}$, respectively, on List 1 but 766 and $703 \mathrm{msec}$, respectively, on List $2[F(1,28)=10.04, p<.005]$. This interaction was probably caused by an inadvertent confounding of familiarity of the targets with the distance condition. An average of $93 \%$ of the subjects knew the correct locations of the six targets in the close condition on List 1 , but an average of only $79 \%$ of the subjects knew the correct locations of the six targets in the far condition on List 1 . The assignment of targets to distance conditions was reversed on List 2: The familiar targets appeared in the far condition and the unfamiliar targets appeared in the close condition. The pattern of this interaction $(+48$ msec distance effect on List 1 and -63-msec distance effect on List 2) indicates that there was no effect of spatial priming in this experiment, not even a small one obscured by familiarity.

Mean correct response latencies and mean error rates were $777 \pm 19 \mathrm{msec}$ and $5.8 \pm 1.2 \%$, respectively, for primes, $946 \pm 24 \mathrm{msec}$ and $8.8 \pm 1.3 \%$, respectively, for foils, and $820 \pm 26 \mathrm{msec}$ and $21.7 \pm 2.7 \%$, respectively, for fillers. The mean latency for errors was 1,017 $\pm 49 \mathrm{msec}$.

\section{Discussion}

Experiments 1 and 2 demonstrated that the subjects were able to retrieve the names of buildings on the campus without retrieving, or activating, knowledge about the locations of those buildings. This result is consistent with that of Merrill and Baird's (1987) fourth experiment, which also found no evidence of purely spatial priming. Although these findings may not seem surprising given the varied contexts in which campus buildings are experienced (many of which, such as planning course schedules, are nonspatial), they contrast sharply with our previous work on memory for experimentally learned environments.

Our previous research on spatial memory can be reconciled with the results of Experiments 1 and 2 (as well as with those of Experiment 4 of Merrill \& Baird, 1987) if the nature of the learning situation is examined carefully. When environments are learned in an experimental setting, the identities (names or appearances) and the locations of objects are experienced in the same, restricted context. The decision about whether or not an object is in an environment must be based on these highly contextualized and necessarily spatial experiences. In contrast, when environments (e.g., campuses) are learned naturally, the identities and the locations of objects are experienced in many different contexts. As a consequence, recognition decisions can be based on sources of familiarity that are not spatial and, therefore, spatial priming does not occur. This analysis suggests that spatial priming will not appear in natural spatial memory unless the task requires subjects to retrieve spatial information. 


\section{EXPERIMENT 3}

The goal of Experiment 3 was to change the recognition test in such a way that the subjects would be more likely to retrieve spatial information as part of the decision process. An obvious way to accomplish this goal would be to have subjects judge the absolute or the relative locations of buildings (see, e.g., Clayton \& Chattin, 1989). We decided not to pursue these options for two reasons: first, we wanted to use a task that was as similar as possible to the recognition task used in our earlier work; and second, we wanted the task to have minimal spatial demands.

The simplest change, it seemed to us, was to change the foils. In particular, we sought to replace the foils with names of buildings in the Vanderbilt area, so that deciding whether or not a building was on the campus would require some spatial information. The Vanderbilt campus is organized ideally for this kind of experiment. Vanderbilt University and George Peabody College for Teachers merged in 1979. These campuses are separated by a major thoroughfare and offset on the north-south axis (see Figure 1). (Wesley Hall is an exception; it is part of the Vanderbilt campus but is on the same side of the street as the Peabody campus.) Although only a minority of students (education majors) have regular classes on the Peabody campus, several dormitories are located there. Consequently, advanced students would be familiar with many of the buildings on the Peabody campus. In Experiment 3, we replaced the fictional building names used as foils in Experiments 1 and 2 with names of buildings on the Peabody campus. The subjects' task was to decide whether a building was on the main Vanderbilt campus or on the Peabody campus. We hoped that this change would inject a spatial element into the decision process, thereby forcing the subjects to retrieve at least some knowledge about the spatial properties of these environments.

\section{Method}

Subjects. The subjects were 26 juniors and seniors at Vanderbilt University. The subjects were compensated for their participation in the experiment with course credit.

Materials. The 12 targets and 8 fillers used in Experiments 1 and 2 were also used in Experiment 3. One of the 18 primes, West Side Row, was replaced by a new building, Tolman, because fewer than $60 \%$ of the subjects in Experiment 2 knew the location of West Side Row. With this change, the average distance between targets and their close primes was $350 \pm 45 \mathrm{ft}$ (distances between targets and their far primes did not change). In addition, the names of two primes were shortened: Owen Graduate School became Owen and Stevenson Center became Stevenson. The full-length names were used in Experiments 1 and 2 because we wanted the test items to be as specific as possible. However, responses on the buildinglocation test used in Experiment 2 indicated that students naturally referred to these buildings with the shorter names.

Two targets (Rand and Branscomb) were moved from the close condition to the far condition of List 1, and two other targets (Neely and Garland) were moved from the far condition to the close condition of List 1 (corresponding changes were made in List 2). These changes were made to better equate the familiarity of targets in the close and far conditions within a list (familiarity was equated perfectly across lists because each target appeared in each experimental condition). Based on the knowledge-test results of Experiment 2, $85 \%$ of the subjects, on the average, knew the locations of the target buildings in the close condition of List 1 and $88 \%$ of the subjects, on the average, knew the locations of the target buildings in the far condition of List 1 (these buildings appeared in the far and in the close conditions, respectively, on List 2). A list of the materials can be found in Appendix B.

Procedure. The subjects first participated in the practice recognition test, in which they discriminated names of U.S. states from names of foreign countries. The subjects were then given the experimental recognition test. The subjects were told that they would see names of buildings appearing one at a time on the computer screen; their task was to decide, as quickly and as accurately as possible, whether the building was on the main Vanderbilt campus or on the Peabody campus. The subjects pressed the " $\mathrm{m}$ " key for Vanderbilt buildings and the " $z$ " key for Peabody buildings. After the recognition test, the subjects were given the building-location knowledge test used in Experiment 2. The subjects' knowledge of buildings on the Peabody campus was not tested. An experimental session lasted about $30 \mathrm{~min}$.

\section{Results}

Mean correct response latencies and mean error rates for the targets in each of the two conditions were analyzed. Only correct responses preceded by correct responses were included in these means. Latencies exceeding $3.5 \mathrm{sec}$ were excluded as well (this cutoff is consistent with the longer response latencies in the experiment). Out of 281 responses that met the first condition, 2 were classified as outliers.

The mean latency for targets primed by a close building was $1,066 \mathrm{msec}$, and the mean latency for targets primed by a far building was $1,177 \mathrm{msec}[t(25)=1.80$, $S E D=61.6 \mathrm{msec}, p=.043] .{ }^{3}$ Error rates were $0.6 \%$ and $2.6 \%$, respectively $[t(25)=1.81, S E D=1.1 \%, p=$ $.041]$. Thus, the spatial priming effect appeared both in latencies and in errors in Experiment 3. Mean latencies were longer in this experiment than in Experiments 1 and 2 , which is to be expected, given that the task was more difficult.

On the average, the subjects knew the correct locations and names of $89.4 \pm 1.7 \%$ of the 30 buildings on which they were tested in the posttest. The spatial priming effect was still reliable when analyses of latencies were conditionalized on performance on the building-location test. There was some indication of an interaction between the distance effect and recognition-test list $(+84 \mathrm{msec}$ on List 1 and $+136 \mathrm{msec}$ on List 2), but unlike in Experiment 2 , this interaction was ordinal and not statistically reliable $(F<1)$.

Mean correct response latencies and mean error rates were $1,173 \pm 42 \mathrm{msec}$ and $8.3 \pm 1.6 \%$, respectively, for primes; $1,381 \pm 54 \mathrm{msec}$ and $21.6 \pm 2.0 \%$, respectively, for foils (i.e., names of buildings on the Peabody campus); and $1,196 \pm 56 \mathrm{msec}$ and $21.6 \pm 2.9 \%$, respectively, for fillers. The mean latency for errors was $1,486 \pm 67 \mathrm{msec}$. 


\section{Discussion}

The major result from Experiment 3 was that the subjects recognized that a building was on the Vanderbilt campus faster and more accurately when that item was preceded immediately by a nearby campus building than when it was preceded immediately by a far campus building. Although the materials used in Experiment 3 required the subjects to use some spatial information, namely, whether a building was on the main Vanderbilt campus or on the Peabody campus, these materials did not require the subjects to use their knowledge of the spatial relations between buildings on these campuses (cf. Clayton \& Chattin, 1989). Yet the distance effect in priming indicates that the subjects' decisions were influenced by these "irrelevant" spatial interrelations.

A problem with Experiments 1-3 was that differences between conditions were confounded with irrelevant differences between experiments. Experiment 4 was designed to remedy this problem.

\section{EXPERIMENT 4}

Three groups were used in Experiment 4. In the Campus/Fictional-foil (Campus/F) group, the subjects received a recognition test for Vanderbilt buildings. Foils in this test were the fictional building names used in Experiments 1 and 2. In the Campus/Peabody-foil (Campus/P) group, the subjects also received a recognition test for Vanderbilt buildings, but the foils were names of buildings on the Peabody campus. Finally, in the Map group, the subjects first learned a map of a fictional campus. Unbeknownst to subjects, the locations on this map corresponded to locations of buildings on the Vanderbilt campus. In other words, the fictional map was obtained from a real map of the Vanderbilt campus by replacing real building names with fake ones (e.g., Underwood was replaced by Woodruff). After learning the map, the subjects received a recognition test in which the targets were the names of buildings on the map and the foils were the fictional names used in Experiments 1 and 2 and the Campus/F group.

The first two groups replicated Experiments 1-3 in a single experiment. The Map group was included because we wanted to demonstrate that a spatial priming effect would appear in recognition if the configuration of buildings was learned experimentally. ${ }^{4}$

\section{Method}

Subjects. The subjects were 120 Vanderbilt undergraduates, 40 in each of three groups. The subjects were randomly assigned to the three groups and received course credit for their participation in the experiment.

Materials. For the Campus/F group, test lists were obtained from the lists used in Experiment 3; however, West Side Row replaced Tolman (see Note 3 ) and the Peabody names were replaced by the fictional foils used in Experiments 1 and 2. Hence, these lists were very similar to the lists used in Experiments 1 and 2.

For the Campus/P group, test lists were identical to those used in Experiment 3, except that West Side Row replaced Tolman.
For the Map group, a map of the Vanderbilt campus (not including the Peabody campus) was constructed. A replica of this map can be found in Figure 2. Each location on this map corresponded to the location of a real building on the Vanderbilt campus. For example, the buildings McGugin and Hemingway in Figure 1 correspond to Sherman and Kline in Figure 2 . The names of the buildings on this map were fictional and had no obvious relation to names of real buildings on the campus. The subjects learned the locations of these fictional buildings in the first phase of the experiment.

After learning the map, the subjects received an item-recognition test. The test lists corresponded to those used in the Campus/F group, except that the real building names (e.g., Buttrick) were replaced by their corresponding fictional names on the map (e.g., Wilson).

Procedure. The procedures used in the Campus/F and the Campus/P groups were the same as those used in Experiments 2 and 3 , respectively.

The subjects in the Map group first had to learn the locations of buildings on the map. The subjects were allowed to study the map for 2 min. At that point, the subjects were given a test map that contained locations of buildings, but not their names, and a list of the building names. The subjects were asked to place all of the building names on their correct locations. The subjects placed as many names as possible and then had their work checked by the experimenter. This sequence was repeated until the subjects could place all of the names correctly twice. None of the subjects recognized that the map actually depicted the relative locations of buildings on the Vanderbilt campus. After learning the map, the subjects received a recognition test for buildings on the map. The procedures for this test were the same as those used in Experiment 2. The subjects in the Map group were not tested on their knowledge of the Vanderbilt campus.

\section{Results and Discussion}

Mean response latencies for targets in each of the two conditions were analyzed. ${ }^{5}$ The groups were analyzed separately because of substantial differences in withingroup variances. Response latencies exceeding the upper, outer fence (Tukey, 1977) for each condition were classified as outliers and were excluded from analyses of latencies. ${ }^{6}$ An average of $3.0 \%$ of the latencies were excluded across the three groups. Mean latencies for each group and each condition can be found in Table 1 .

The effect of distance was not reliable in the Campus/F group $[t(39)=1.15, S E D=12.9]$. This result replicates the results of Experiments 1 and 2. However, this effect was reliable in the Campus/P group $[t(39)=3.50, S E D$ $=22.0, p<.001]$, which replicates the results of Experiment 3 . Finally, the distance effect was reliable in the Map group $[t(39)=2.18, S E D=12.6, p<.018]$.

For the Campus/F group, mean response latencies and error rates were $693 \pm 12 \mathrm{msec}$ and $10.6 \pm 1.4 \%$, respectively, for primes; $783 \pm 11 \mathrm{msec}$ and $12.7 \pm 1.3 \%$, respectively, for foils; and $719 \pm 27 \mathrm{msec}$ and $23.8 \pm 2.4 \%$, respectively, for fillers. The mean latency for errors was $840 \pm 23 \mathrm{msec}$. For the Campus/P group, mean latencies (including errors; see Note 5) were $937 \pm 20 \mathrm{msec}$ for primes, $1,028 \pm 19 \mathrm{msec}$ for foils (i.e., Peabody buildings), and $961 \pm 28 \mathrm{msec}$ for fillers. Finally, for the Map group, mean response latencies and error rates were $668 \pm 12 \mathrm{msec}$ and $2.3 \pm 0.7 \%$, respectively, for primes; $720 \pm 9 \mathrm{msec}$ and $5.3 \pm 0.9 \%$, respectively, 


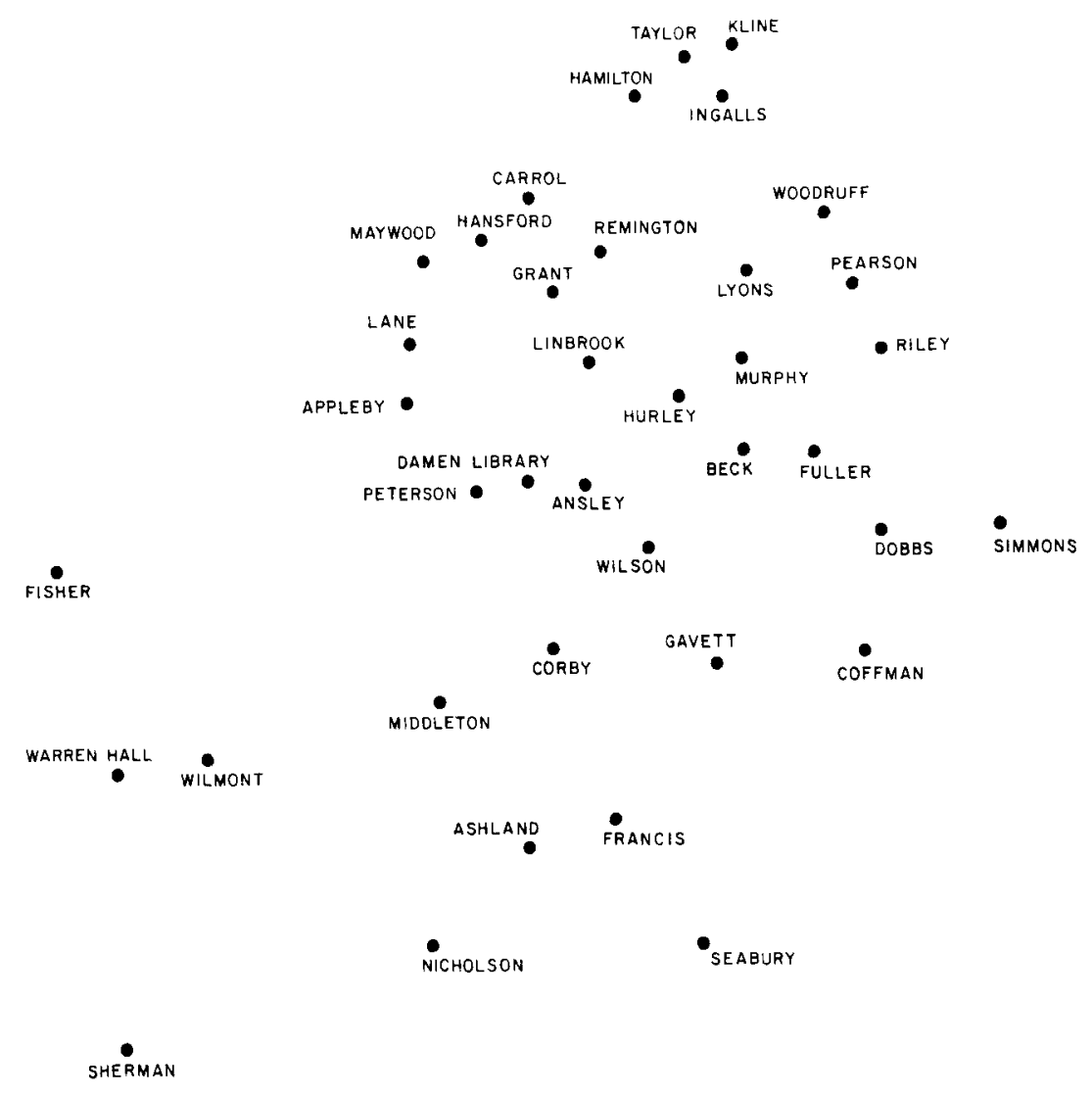

Figure 2. A replica of the map learned by subjects in the Map group of Experiment 4. "Sherman" and "Kline" in Figure 2 correspond to "McGugin" and "Hemingway" in Figure 1.

for foils; and $745 \pm 20 \mathrm{msec}$ and $4.1 \pm 1.1 \%$, respectively, for fillers. The mean latency for errors was $753 \pm 42 \mathrm{msec}$.

\section{GENERAL DISCUSSION}

The results from these experiments indicate that spatial priming does not occur when subjects' memories are probed for the presence or absence of buildings on their campus, unless the task requires the subjects to use their knowledge of the locations of buildings. This finding probably explains why Merrill and Baird (1987) did not find clear evidence of purely spatial priming in their experiments: The task used by Merrill and Baird did not require subjects to use spatial knowledge. This dependency of spatial priming on the items used as foils parallels, in cer-

Table 1

Mean Response Latencies (in msec) and Error Rates (\%) in Experiment 4

\begin{tabular}{llllll}
\hline & \multicolumn{2}{c}{ Close } & & \multicolumn{2}{c}{ Far } \\
\cline { 2 - 3 } \cline { 5 - 6 } & RL & ER & & RL & ER \\
\hline Campus/Fictional-Foil & 650 & 5.4 & 665 & 5.8 \\
Campus/Peabody-Foil & 808 & & 885 & \\
Map & 621 & 1.7 & 649 & 2.1 \\
\hline
\end{tabular}

Note-RL $=$ response latency. ER $=$ error rate. Error rates were not available for the Campus/Peabody-foil group (see Note 5). tain respects, the dependency of priming in lexical decisions on the nonwords used as distractors (e.g., Davelaar, Coltheart, Besner, \& Jonasson, 1978; McNamara \& Healy, 1988; Shulman \& Davison, 1977; Shulman, Hornak, \& Sanders, 1978).

The findings reported here are surprising in the context of research on memory for experimentally learned environments, which has demonstrated repeatedly that spatial priming occurs even when the task does not require subjects to use their knowledge of spatial relations. As noted earlier, this paradox can be resolved by examining differences between experimental and natural spatial learning. When people learn a spatial layout or a map in an experiment, the initial memory representation is a highly contextualized, unitary representation of object identities (e.g., name codes or interpreted images) and locations. Consequently, subjects cannot retrieve the name of an object without also retrieving the location of that object. One result of these interdependencies is that objects close to each other in a spatial layout and, consequently, "close" to each other in memory, prime each other in recognition tests, even though the recognition task does not require subjects to retrieve knowledge about these spatial interrelations. However, when spatial environments are learned over long periods of time and objects in those environments are experienced in different con- 
texts (Evans \& Pezdek, 1980), the identities and the locations of objects become dissociated, possibly leading to multiple internal representations. A consequence of multiple sources of familiarity, or multiple internal representations, is that names of buildings can be retrieved from memory without activating spatial knowledge.

The interdependence of item and location information in memory has been investigated quite extensively (e.g., Mandler, Seegmiller, \& Day, 1977; Park \& Mason, 1982; Pezdek, Roman, \& Sobolik, 1986; Rothkopf, 1971; Salthouse, 1974; Schulman, 1973). This research has examined whether or not locations of objects are encoded automatically in tasks that require memory for object identity. In a prototypical experiment, subjects are asked to remember the identities of objects in a spatial array, but are later tested on their memory for the objects' locations. This research indicates that locations of real objects are encoded automatically, but that locations of words and text may or may not be so encoded, depending on the situation (Pezdek et al., 1986).

These results seem to contradict those of the present experiments. In the present study, subjects retrieved item and location information independently from their memories of a campus, but they could not retrieve this information independently from their memories of a map. This tension may be more apparent than real. First, all of our research has examined intentionally learned spatial layouts; even the learning of a campus is intentional, although it may take place over a relatively long period of time. We suspect that under intentional learning conditions, subjects always encode item and location information together, regardless of whether the items are objects or words (e.g., McNamara, 1986). As stated above, the difference between naturally acquired and experimentally acquired spatial memories exists in the "decontextualization" that takes place in the former but not in the latter. Second, there is an important conceptual difference between memory for absolute spatial position and memory for relative spatial position. To our knowledge, only the former has been examined in the work on item and location memory; however, it is probably the latter that is responsible for spatial priming effects in recognition. In sum, we view these two lines of research as complementary rather than as contradictory. Future research is certainly needed to clarify these issues.

One might be tempted to assign memories of experimentally learned environments to one memory system, say "episodic," and memories of naturally learned environments to another memory system, say "semantic" (e.g., Tulving, 1983). We prefer to think of these types of memories as endpoints on a developmental continuum rather than as qualitatively different types of memory. This view leads naturally to longitudinal investigations of spatial memories as they move from contextualized states to decontextualized states. Research along these lines would be informative about the development of spatial memory. Perhaps more importantly, however, such research might tell us about how our experiences in space and time eventually become knowledge of the world.

\section{REFERENCES}

Clayton, K. N., \& Chattin, D. (1989). Spatial and semantic priming effects in tests of spatial knowledge. Journal of Experimental Psychology: Learning, Memory, \& Cognition, 15, 495-506.

Davelaar, E., Coltheart, M., Besner, D., \& Jonasson, J. (1978). Phonological recoding and lexical access. Memory \& Cognition, 6 , $391-402$

Evans, G. W., \& Pezdek, K. (1980). Cognitive mapping: Knowledge of real-world distance and location information. Journal of Experimental Psychology: Human Leaming \& Memory, 6, 13-24.

HirTle, S. C., Jonides, J. (1985). Evidence of hierarchies in cognitive maps. Memory \& Cognition, 13, 208-217.

Mandler, J. M., Seegmiller, D., \& Day, J. (1977). On the coding of spatial information. Memory \& Cognition, 5, 10-16.

MCNamara, T. P. (1986). Mental representations of spatial relations. Cognitive Psychology, 18, 87-121.

McNamara, T. P., Hardy, J. K., Hirtle, S. C. (1989). Subjective hierarchies in spatial memory. Journal of Experimental Psychology: Learning, Memory, \& Cognition, 15, 211-227.

McNamara, T. P., Healy, A. F. (1988). Semantic, phonological, and mediated priming in reading and lexical decisions. Joumal of Experimental Psychology: Leaming, Memory, \& Cognition, 14, 398-409.

McNamara, T. P., \& LeSueur, L. L. (in press). Mental representations of spatial and nonspatial relations. Quarterly Journal of Experimental Psychology: Human Experimental Psychology.

McNamara, T. P., Ratcliff, R., \& McKoon, G. (1984). The mental representation of knowledge acquired from maps. Journal of Ex perimental Psychology: Leaming, Memory, \& Cognition, 10, 723-732.

MerRILl, A. A., BAIRD, J. C. (1987). Semantic and spatial factors in environmental memory. Memory \& Cognition, 15, 101-108.

PARK, D. C., \& MASON, D. (1982). Is there evidence for automatic processing of spatial and color attributes present in pictures and words? Memory \& Cognition, 10, 76-81.

Pezdek, K., Roman, Z., \& Sobolik, K. G. (1986). Spatial memory for objects and words. Joumal of Experimental Psychology: Leaming, Memory, \& Cognition, 12, 530-537.

Posner, M. I., \& SNyder, C. R. (1975a). Attention and cognitive control. In R. L. Solso (Ed.), Information processing and cognition. (pp. 55-85). Hillsdale, NJ: Erlbaum.

PosNer, M. I., SNYDER, C. R. (1975b). Facilitation and inhibition in the processing of signals. In P. M. A. Rabbitt (Ed.), Attention and performance (Vol. 5, pp. 669-682). London: Academic Press.

RatclifF, R., \& MCKoon, G. (1981). Automatic and strategic priming in recognition. Journal of Verbal Learning \& Verbal Behavior, 20, 204-215.

RoTHKOPF, E. Z. (1971). Incidental memory for location of information in text. Joumal of Verbal Learning \& Verbal Behavior, 10, 608-613.

Salthouse, T. A. (1974). Using selective interference to investigate spatial memory representations. Memory \& Cognition, 2, 749-757.

Schulman, A. I. (1973). Recognition memory and the recall of spatial location. Memory \& Cognition, 1, 256-260.

Shulman, H. G., \& Davison, T. C. B. (1977). Control properties of semantic coding in a lexical decision task. Journal of Verbal Learning \& Verbal Behavior, 16, 91-98.

Shulman, H. G., Hornak, R., \& Sanders, E. (1978). The effects of graphemic, phonetic, and semantic relationships on access to lexical structures. Memory \& Cognition, 6, 115-123.

Stevens, A., \& Coupe, P. (1978). Distortions in judged spatial relations. Cognitive Psychology, 10, 422-437. 
ThoRndyke, P. W., \& Hayes-Roth, B. (1982). Differences in spatial knowledge acquired from maps and navigation. Cognitive Psychology, 14, 560-589.

TUKEY, J. W. (1977). Exploratory data analysis. Reading, MA: Addison-Wesley.

Tulving, E. (1983). Elements of episodic memory. Oxford: Oxford University Press.

\section{NOTES}

1. Merrill and Baird's (1987) procedures guaranteed that their subjects were familiar with the buildings but did not guarantee that the subjects knew the relative locations of buildings. Spatial priming depends on both of these factors.

2. $S E D=$ standard error of the difference. Statistical tests of distance effects were directional. One-tailed tests were appropriate given our previous research on similar problems.

3. Due to an oversight, McGill and its new close prime Tolman were both dormitories. When this item was excluded, means were $1,083 \mathrm{msec}$ for the close condition and $1,191 \mathrm{msec}$ for the far condition $[t(25)=1.66$, $p=.055]$. Thus, the size of the distance effect is essentially the same (108 vs. $111 \mathrm{msec}$ ) regandless of whether this item is excluded or included. The slight reduction in statistical reliability is to be expected given that this item accounted for 26 out of the 279 latencies analyzed in Experiment 3.

4. We considered having naive subjects learn the locations of actual buildings on the campus. We quickly rejected this idea, however, when we discovered that visiting every building on campus required about $3 \mathrm{~h}$. Given that subjects typically need about four trials, on the average, to learn locations of real objects in large spatial layouts (e.g., McNamara, 1986), the learning phase of such an experiment would require about $12 \mathrm{~h}$. In addition, in previous studies, we found no differences in the structure or the content of spatial memories acquired from maps as opposed to navigation (McNamara, 1986; McNamara et al., 1989). Differences that have been found have been limited to orientation judgments and to route (but not Euclidean) distance estimation (Evans \& Pezdek, 1980; Thomdyke \& Hayes-Roth, 1982). For these reasons, the Map group was probably adequate for the purposes of this experiment.

5 . Because of a problem in the program used for stimulus presentation and data collection, responses were not recorded for the Campus/P group. Thus, we could not determine whether or not these subjects made an error on a given trial. To make the results from the three groups as parallel as possible, we decided to present the results for all three groups with errors included in the mean response latencies. The results for the Campus/F and Map groups did not change when the errors were excluded.

6. The upper, outer fence is equal to the 75th percentile $+[3 \times$ (75th -25 th)].

\section{APPENDIX A \\ Materials Used in Experiments 1 and 2}

The first six targets were paired with their far primes on List 1 and with their close primes on List 2 . The second six targets had the opposite assignments.

\begin{tabular}{|c|c|c|}
\hline Targets & Close Primes & Far Primes \\
\hline $\begin{array}{l}\text { McGill } \\
\text { Fine Arts } \\
\text { Neely } \\
\text { Furman } \\
\text { Garland } \\
\text { Benson }\end{array}$ & $\begin{array}{l}\text { West Side Row } \\
\text { Vanderbilt Hall } \\
\text { Alumni Hall } \\
\text { Law School } \\
\text { Divinity School } \\
\text { Calhoun }\end{array}$ & $\begin{array}{l}\text { Owen Graduate School } \\
\text { Underwood } \\
\text { Wesley } \\
\text { Stevenson Center } \\
\text { Langford } \\
\text { Olin }\end{array}$ \\
\hline $\begin{array}{l}\text { McTyeire } \\
\text { Cole } \\
\text { Rand } \\
\text { Kirkland } \\
\text { Branscomb } \\
\text { Heard Library }\end{array}$ & $\begin{array}{l}\text { University Club } \\
\text { Sarratt } \\
\text { Buttrick } \\
\text { Barnard } \\
\text { Memorial Gymnasium } \\
\text { Godchaux }\end{array}$ & $\begin{array}{l}\text { Owen Graduate School } \\
\text { Underwood } \\
\text { Wesley } \\
\text { Stevenson Center } \\
\text { Langford } \\
\text { Olin }\end{array}$ \\
\hline
\end{tabular}

\begin{tabular}{l}
\multicolumn{1}{c}{ Fillers } \\
\hline McGugin \\
Parmer \\
Alexander \\
Mims \\
Currey \\
Reinke \\
Hemingway \\
Bryan
\end{tabular}

\begin{tabular}{ll} 
& Foils \\
\hline Dreyfus & Landau \\
Hoch & Coolidge \\
Suffolk Hall & MacGregor \\
Stratton & Lowell \\
Hermann & Burton Center \\
Sloan & Hayden Library \\
Fraser & Kresge \\
Sterling & McCormick
\end{tabular}




\section{APPENDIX B}

Materials Used in Experiment 3

The first six targets were paired with their far primes on List 1 and with their close primes on List 2 . The second six targets had the opposite assignments.

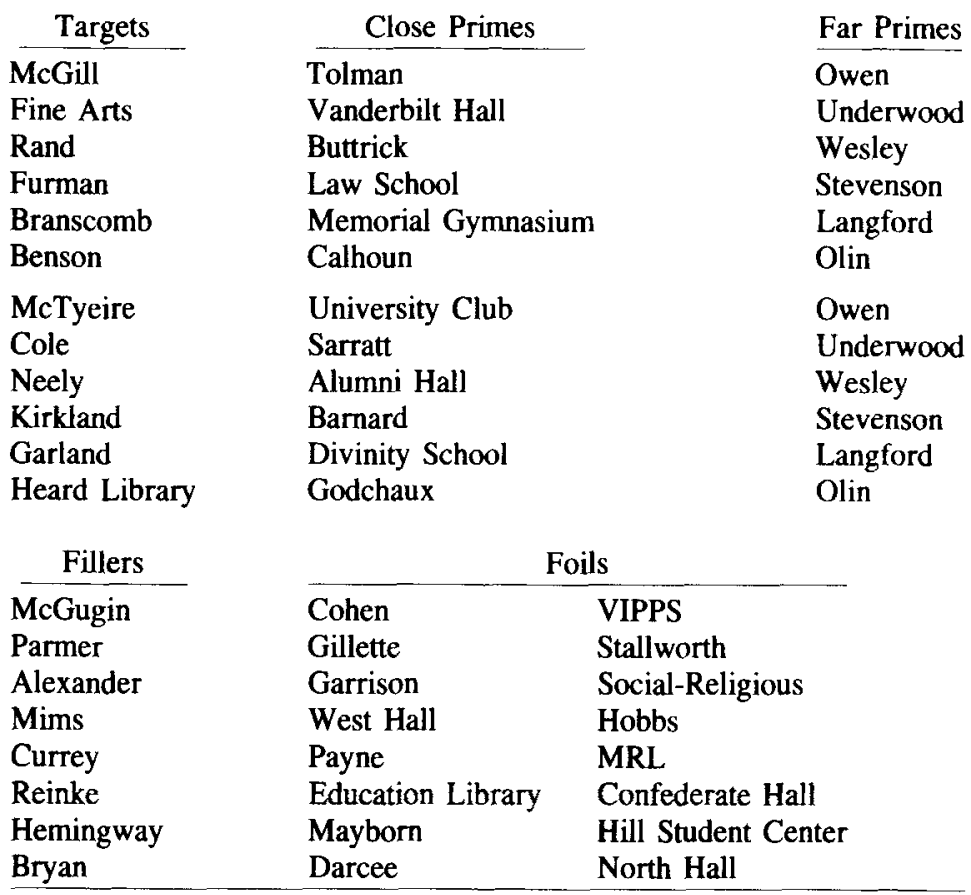

(Manuscript received April 7, 1987;

revision accepted for publication October 31,1988 .) 